discurso (22), 1993: 205-221

\title{
A Retórica da Economia segundo McCloskey
}

Bento Prado Junior

Mark Julian R. Cass*

Resumo: O tema é o programa de reavaliação filosófica da retórica da economia proposta por MoCloskey. Bento Prado ( I e II) argumenta que uma teoria da retórica para a qual "vale tudo" não deveria ser inferida da justa crítica que MoCloskey endereça ao positivismo. Em III (M. Julian Cass) são discutidas algumas aporias filosóficas presentes nos textos de MoCloskey.

Palavras-chave: economia - filosofia da economia - positivismo - retórica

Ce que les anciens ont fait avec $l^{\prime}$ éloquence est prodigieux... Jean Jacques Rousseau

...tandis que notre civilization, caracterisée par son extrême ingéniosité dans les techniques destinées à agir sur les choses, a complètement oublié la théorie de l'argumentation, de l'action sur les esprits au moyen du discours, celle-ci était considérée par les Grecs, sous le nom de rhétorique, comme la 'techné' par excellence.

Ch. Perelman e Olbrechts-Tyteca

Não é apenas o estilo ágil e alegremente anárquico dos textos de McCloskey que torna agradável o trabalho de comentá-lo. Uma vez que 
"the best way to see someone's point is auto-biography"(1), vale indicar, de saída, como os textos de McCloskey cruzaram antigas preocupações de ambos os comentadores: um de nós está atualmente escrevendo sobre modelos explicativos em Economia, enquanto o outro estudou, alguns anos atrás, a Retórica Clássica e sua radical reformulação por Rousseau, cuja concepşão essencialmente retórica da linguagem (isto é, livre dos limites ditados pela gramática e pela lógica de Port-Royal) abre caminho para uma teoria unificada, capaz de dar conta, ao mesmo tempo, da Antropologia, da Teoria Política e das Belas Letras: uma espécie de Retórica Generalizada que antecipa a tentativa de nosso autor de estabelecer um canal de ligação entre a Teoria das Ciências Humanas e a Teoria da Literatura. Mais ainda, nos seminários de nosso "Laboratório de Epistemologia da Psicologia e da Psicanálise", dedicados ao que decidimos chamar de "aporias do pós-behaviorismo", examinamos as dificuldades encontradas por psicólogos experimentais ao usarem a retórica do positivismo lógico para descrever suas pesquisas.

Esta auto-referência não é arbitrária. Estávamos em condições de vislumbrar, de saída, a força dos textos de MoCloskey - a saber, a maneira pela qual ele tenta alcançar um alvo ou um público definido. Enfim, isto nos permitia reconhecer a natureza retórica ou polêmica da Retórica da Economia. Assim, a despeito de sua démarche errante e sinuosa, seu dbjetivo parecia perfeitamente claro: mostrar a completa incompatibilidade entre a prática real dos economistas e a autoconsciência epistemológica ou metodológica com a qual justificam essa prática. Esta acre polêmica contra os resícuos do positivismo na consciência (filósofos decididamente gostam de itálicos ) dos economistas tem o ar de uma psicanálise do conhecimento científico: trazer à luz o que foi recalcado pelo super-ego tirânico de uma metodologia positivista" (2) Quando diz que "rhetoric is good for you", McCloskey parece estar atribuindo à retórica uma propriedade catártica ou terapêutica. Estamos, portanto, num terreno familiar. E para balisá-lo de maneira tão clara quanto possível, não devemos temer nem simplificação nem esquematismo. Elevado ao éter da filosofia, o argumento de MoCloskey pode ser descrito da seguinte forma: nenhuma teoria econômica pode ser entendida se nos restringirmos aos pólos da forma lógica e dos dados observacionais. É este dualismo cátaro, que postula a total independência entre linguagem e mundo (pressuposto da filosofia analítica, mas que ela abandonou assim que descobriu a irremediável promiscuidade entre o a priori e o a posteriori, o analítico e o sintético) , que precisa ser superado, segundo McCloskey (que, neste ponto, segue Quine, Sellars e Goodman ), nas cabeças estreitas dos economistas. De um lado, o holismo da nova filosofia da linguagem (não é preciso ser um renegado para vê-lo) repete o dictum nietzchiano: Es gibt keine Tatsache, nur Interpretationen (que se pense, aqui, em Sellars, Goodman, Quine etc). De outro, os limites da tradução, da redução e da formalização restauram, de modo não dualista, o dictum kantiano - "O conceito sem intuição é vazio, a intuição sem conceito é cega" -, como Goodman o faz explicitamente em seu Ways of Worldmaking ( Hackett Publ. Co., 1985, p. 6 ) . Mas, acima de tudo, parece que, como em Kant, essa síntese requer, além do já referido dualismo, algo como uma terceira instância, que não é mais puramente lógica, mas que certamente não é ainda empírica (pelo menos no sentido de "proposições observacionais") . Isto é, como Foucault o descreveria, caminhamos para o reconhecimento de um domínio do "misto" na epistemologia contemporânea, de um discurso ao mesmo tempo empírico e transcendental. Em suma, com esta mutação teórica, o estilo da filosofia transcendental começa a infiltrar-se sorrateiramente no tranquilo coração da filosofia analítica.

Mas a polêmica de MoCloskey não é meramente destrutiva ou negativa, nem se limita a opor a boa filosofia contemporânea a uma epistemologia arcaica que, como erva daninha, insiste em brotar entre as linhas dos textos de economistas americanos. A análise lógica dos sistemas teóricos morreu: viva a Retórica! Ali onde o projeto universalista de ciência unificada naufragou, nasceu uma nova disciplina universal, em muito semelhante à Pragmática Universal de Habermas, e que deve ser compreendida. E compreendê-la é compreender como renegar uma concepção estritamente "lógica" do universal não obriga a renunciar à universalidade ou a aceitar a irracionalidade. O projeto de McCloskey só será compreendido se se reconhecer que "rhetoricism is not irrationalism". Estamos frente a uma tese muito clara: a de que não há razão para identificar racionalidade com demonstração apodítica. Trata-se, essencialmente, da tese de que o "razoável" 
- isto é, um argumento que, sem se impor pela mera forma, pode ser persuasivo para uma open mind - não deve ser oposto ao racional como o dia à noite. E, certamente, é "ilógico" confundir o razoável com o irracional. Neste aspecto, o projeto da Retórica Universal participa de um movimento geral do pensamento contemporâneo, que pode ser identificado nas províncias distintas da filosofia analítica, da fenomenologia e do neokantismo. Todas estas tradições partilhavam, de início, o mesmo estilo asperamente "modernista" (para usar a terminologia de MoCloskey ), que só reconhece racionalidade ali onde ela pode ser remetida a seu fundamentum absolutum. Russell, Husserl e a escola de Marburg, cada qual se remetendo de forma diferente à tradição do Racionalismo (Platão, Descartes, Leibniz e Kant), identificam a Razão com o Absoluto, projetando para o limbo da irracionalidade o domínio do empírico, do natural, do psicológico e do histórico. E, no entanto, por uma estranha inversão, um movimento comum parece emergir em cada uma dessas três tradições, durante os anos 20 e 30, que leva a um alargamento da idéia de Razão, acompanhado por uma ênfase crescente nas formas "pré-epistêmicas" de consciência e linguagem, ou nas raízes pré-lógicas ou pré-predicativas do conhecimento (como a procura de um logos estético - para usar a expressão de Merleau-Ponty - na investigação do Lebenswelt, em Heidegger, ou na fenomenologia da expressão, em Cassirer; ou como o logos prático - para usar a expressão de J. A. Giannotti - implícito nas noçães de Sprachspiel e Iebensform do segundo Wittgenstein) . Este segundo movimento se faz o arauto do eclipse das epistemologias fundacionalistas: Heidegger repete a tirada hegeliana, insistindo em que "zu Grund gehen" é precipitar-se num abismo; para Wittgenstein, quando se atinge o solo rochoso ("la pierre et l' argile" de Descartes), repousamos em meras convengões; Cassirer transforma a teoria da ciência numa filosofia da cultura ou das formas simbólicas que abraça, num único gesto teórico, mito, arte e ciência. Mas o ways of worldmaking de Nelson Goodman talvez seja, dentre essas obras filosóficas, a mais congenial à empresa de MoCloskey. Este livro, algo ao modo de Cassirer, visa uma teoria geral do simbolismo que possa explicar os esquemas básicos de simbolização que operam não só no nível lógico-científico, mas na estruturação artística da experiência. Assim, a idéia de verdade é subordinada à idéia mais geral de rightness, que pode ser encontrada na base de nossa experiência da verdade nas linguagens da arte. Num nível diferente e superior ao da epistemologia e da lógica, surge a esfera de uma espécie de metafilosofia que, como o seio de Abraão (o anti-Khomeini), pode abraçar vários mundos possíveis. Esta abertura da mente para diversos ways of worldmaking só é possível para quem de alguma forma modificou sua idéia da verdade graças a uma excursão pelo reino da rightness na representação artística do mundo. Uma lição que parece ter sido aprendida por McCloskey, quando ele nos convida a refinar nossa leitura da Economia pela reflexão sobre a linguagem da Literatura.

Aber bist du kein Pragmatiker? Nein. Denn ich sage nicht, der Satz sei wahr, der nutzlich ist. Der Nutzen, d.h., Gebrauch, gibt dem Satz seinen besondern Sinn, das Sprachspiel gibt ihm ihn.

Wittgenstein

Não há dúvida, portanto, de que McCloskey recorre a instrumentos filosóficos apropriados na sua cruzada contra o positivismo que ainda obscurece a idéia que os economistas americanos têm de sua prática teórica. No entanto, pode-se perguntar se nosso Autor, levado pelo justo impulso de sua polêmica, não foi um pouco longe demais. Em outras palavras, se sua preocupação terapêutica com a higiene do discurso econômico não o levou a jogar o bebê junto com a água do banho.

Não se trata de discordar de McCloskey, mas sim de, tendo aceito seu convite de reanimar o estilo conversacional da tradição da Razão, perguntar se a idéia da Retórica da Economia realmente sugere a moral rortyana que ele parece dela retirar. Minha pergunta é: estamos nós condenados a seguir os passos de Dewey pelo simples fato de recusar a megalomania do fundacionalismo? Ou, em outras palavras, será necessário deitar fora toda 
reflexão epistemológica ao reconhecer, como devemos fazê-lo, a dimensão retórica das ciências humanas? Mais ainda, será que a descrição da Epistemologia apresentada em Philosophy and the Mirror of Nature é razoável? Estamos convencidos de que é perfeitamente possível - e desejável - preservar os aspectos positivos e negativos da polêmica antipositivista de McCloskey, uma vez separados de seu background rortyano. Com esta intervenção cirúrgica, os efeitos estritamente filosóficos da Retórica da Economia, enfim livres da retórica vaga do pragmatismo, podem tornar-se fecundos. Mas de onde a necessidade de uma intervenção cirúrgica? É que por ser excessivamente crua, a arqueologia do modernismo proposta por Rorty pode levar a equívocos que não se restringem à esfera da filologia ou da história das idéias. Comparada com Les Mots et les Choses de Michel Foucault (que não deve ser confundido com Jean-Baptiste Iéon, o físico do século dezenove, como no índice remissivo do livro de MoCloskey), esta é uma arqueologia bem rústica. Rústica, principalmente porque não permite nenhum tipo de distinção além da mera oposição entre fundacionalismo e pragmatismo. Na história da filosofia, assim como no campeonato paulista, há mais times envolvidos além de Palmeiras e Corinthians. Assim, McCloskey escreve, "taking the Rortyan archeology of modernism at its word: Im 1.00"."

"A mais virulenta, aliás, destas críticas menores à metodologia modemista, é que, se tomada ao pé da letra, a metodologia é impossível. Que se considerem de novo os passos do conhecimento modernista, do preditivismo até o dilema de Hume, passando pelo dictum de Kelvin. Se economistas (ou físicos) se confinarem a proposições econômicas (físicas) literalmente conformes a tais passos, eles nada terão a dizer. O ceticismo cartesiano e humiano é um padrão de crença por demais corrosivo para qualquer cientista humano real, como Descartes e Hume sabiam" (3).

O ceticismo humiano não é humano? Parece-nos, ao contrário, perfeito, se não demasiadamente humano, no sentido preciso de que o conheci- mento do mundo externo ou da natureza humana pode dar-se sem uma base última, lógica ou ontológica, da regularidade do mundo fenomenal (que se veja, a este respeito, o belíssimo ensaio de Iebrun acerca de La Boutade de Charring-Cross ${ }^{(4)}$ ). A crença é o que basta para o cientista humiano que não se toma pela Razão Divina ou pelo Demiurgo. Mais ainda - pode-se perguntar - não é a "crença" de Hume mais próxima da "assertabilidade justificada" de Dewey do que do rígido critério cartesiano da evidência racional? O que estamos aqui sugerindo, é que, no empirismo e no racionalismo clássicos, há uma modernidade (no sentido das nossas mais vigorosas filosofias contemporâneas) que nada tem a ver com o modernismo descrito por Rorty, e que, muito ao contrário, é antipositivista avant la lettre-isto é, antes do nascimento da bête noire do antimodernismo. O estudo dos textos epistemológicos de Pascal permite, entre outras coisas, uma visão menos parcial da história da filosofia modema e da própria idéia de epistemologia (principalmente porque Pascal incorpora em sua epistemologia uma perspectiva essencialmente retórica, propondo, ao mesmo tempo, uma teoria da demonstração e da persuasão que inclui uma teoria dos destinatários dos discursos do cientista, do filósofo e do teólogo) .

Mas a questão não é puramente filológica: a simplificação operada por Rorty tem efeitos desastrosos no próprio coração da filosofia. É só porque se redefine a vocação "epistemológica" do racionalismo e do empirismo modernos como fundacionalista por natureza e positivista por vocação (ilusão retrospectiva) que se pode recusar, a priori, toda e qualquer epistemologia. Tais predicados talvez possam ser aplicados à epistemologia mal digerida dos economistas americanos (como podem sê-lo à dos analistas experimentais do comportamento), mas, certamente, eles pouco têm a ver com a idéia de epistemologia em si.

Um corolário pernicioso da definição demasiadamente estreita que McCloskey nos oferece da Epistemologia, é uma demarcacão da Retórica que é ampla e vaga demais. Um imbroglio categorial que se revela também na localização equivocada da idéia aristotélica de dialética ${ }^{(5)}$, que MoCloskey define como conhecimento apodítico: em Aristóteles, dialética e retórica opõem-se à ciência, que é concebida como conhecimento (logicamente) demonstrado. Mais ainda, a dialética é definida por Aristóteles como uma 
disciplina propedêtutica para a ciência - isto é, a arte do pepaidomenon, ou o homem que é capaz de discutir razoável e inteligentemente, sem invocar princípios absolutos. Enfim, o dialético de Aristóteles é aquele gentleman cuja ausência do debate epistemológico contemporâneo na Economia americana é lamentada por McCloskey.

Vamos deixar de lado as minúcias históricas, para concordar com McCloskey e voltar a Aristóteles, que também via a boa educação como uma condição da racionalidade. Mas é a melhor parte da epistemologia contemporânea que leva em conta essas condições pré ou extra-lógicas da constituição do conhecimento científico. Penso aqui, entre outros, em Gilles Gaston Granger (por acaso, o autor de Méthodologie Economique, PUF, 1955 ), que, em seu Essai d' une Philosophie du Style (A. Colin, 1968), subordina o projeto epistemológico à idéia de uma "estilística generalizada" - o que certamente seria do agrado de McCloskey. Uma epistemologia não-fundacionalista que é capaz de contrapor as obras matemáticas de Descartes e Desargues segundo critérios que não são, propriamente falando, lógicos. Em outras palavras, uma Epistemologia que não relega ao domínio do sem-sentido as características do discurso científico ressaltadas por MoCloskey, e que ele sustenta serem necessariamente ignoradas por todo e qualquer epistemólogo.

III

Vamos encerrar este comentário com a discussão de uns poucos trechos dos textos de MoCloskey, que apresentam o que reputamos ser dificuldades típicas.

Primeira objeção: há confusões conceituais ocasionais.

What might have been is an abstraction Remaining a perpetual possibility only in a world of speculation T. S. Elliot
Em seu ensaio, Storytelling in economics, MoCloskey examina estilos de discurso econômico. Ele distingue dois tipos: narrações, e discursos orientados por modelos (ou discursos "metafóricos" ) . Segundo MoCloskey, os usos corretos da narrativa e da metáfora são, às vezes, desvirtuados em Economia. Por exemplo:

"Quando uma metáfora é usada ingenuamente na narração da história, ela se enreda em contradições lógicas, como as que acompanham contrafactuais. . . Se um modelo para uma economia for utilizado para imaginar o que teria acontecido à Inglaterra sem a revolução industrial, então a contradição reside em que uma economia do tipo inglês na verdade passou por uma revolução incustrial. Um mundo em que a Inglaterra de 1780 não produziu uma revolução industrial seria um mundo muito diferente tanto antes como depois de 1789. O modelo quer fazer a omelete sem quebrar os ovos. Ela contradiz a estória." (6)

Para McCloskey, se um modelo é usado para narrar algo que poderia ocorrer, mas não aconteceu, ele vai contradizer logicamente a história. 0 problema, continua ele, tem a ver com o caráter contrafactual de relatos deste tipo. Vamos argumentar que MoCloskey se equivoca quanto à natureza do problema: um "modelo" empregado para imaginar o que poderia acontecer mas não ocorreu não entra em contradição com a história, e o que ele encara como uma "contradição lógica" é apenas um desacordo com uma doutrina metafísica que ele parece defender.

Um contrafactual é uma proposição condicional cujo antecedente e, segundo alguns, cujo consequiente são falsos. Proposições contrafactuais têm a propriedade, às vezes vista como paradoxal, de serem sempre verdadeiras. A razão disto pode ser brevemente exposta. Uma proposição condicional nega que seu antecedente possa dar-se quando seu consequiente não se dá. A proposição "Se o XV de Novembro de Jaú vencer, ele vai se sagrar campeão" nega que as proposições "O XV de Novembro de Jaú venceu" e "O XV de Novembro de Jaú não se sagrou campeão" possam ser ambas 
verdadeiras. Agora, com relação a condicionais contrafactuais, a conjunção das proposições negadas inclui pelo menos uma que é falsa; portanto, a conjunção é falsa. Como um condicional contrafactual nega uma conjunção falsa, ele só pode ser verdadeiro.

Robert Graves, em I, Claudius, dá um bom exemplo de uma proposição contrafactual:

"Se o cavalo de Tróia tivesse procriado, a alimentação dos cavalos, hoje, seria bem mais barata". (7)

De uma maneira geral, se isto ou aquilo tivesse ocorrido (e não ocorreu), aquiloutro ocorreria.

Que estória esse exemplo contradiz? A seguinte: o cavalo de Tróia teve cria, e a alimentação dos cavalos, hoje, não é mais barata. E não, como quereria MoCloskey, a proposição "O cavalo de Tróia não procriou", como pode ser visto se inserimos esse exemplo no argumento de MoCloskey contra o uso de contrafactuais:

"Quando uma metáfora é usada ingenuamente na narração da história, ela se enreda em contradições lógicas, como as que acompanham contrafactuais. Se um modelo é utilizado para imaginar o que ocorreria se o cavalo de Tróia tivesse procriado, então a contradição é que o cavalo de Tróia não procriou."

MoCloskey se opõe ao uso de contrafactuais porque eles contradizem narrações verídicas de fatos. Mas ele se equivoca: eles contradizem narrações inverídicas de fatos, e são, portanto, verdadeiros.

MoCloskey errou na explicitação de suas dúvidas, embora talvez não em tê-las. Um dos problemas com os contrafactuais é que, às vezes, eles parecem não nos levar a lugar algum. Como dizia Claudius: "que esplêndida chance ele teve de ser lembrado pela história como 'Calígula, o Bom', ou 'Calígula, o Sábio', ou 'Calígula, o Redentor' . Mas é ocioso escrever desse jeito. Pois se ele tivesse sidb o tipo de homem que pensavam que ele era, ele nunca teria sobrevivido a seus imãos nem sido escolhido por Tiberius como seu sucessor." (8)

Dado que McCloskey é americano e fala inglês, é razoável perguntar se se ganha algo ao dizer "se ele fosse francês, ele falaria francês" ou "se ele fosse alemão, ele falaria alemão" etc. E, é claro, não há limite para a proliferação de contrafactuais. Em The Rhetoric of Economics, MoCloskey parece reconhecer esses problemas:

Proposições condicionais são baratas: se o mar desaparecesse, uma pedra aceleraria, ao cair do nível do mar para o fundo do mar, a cerca de $9,8 \mathrm{~m} / \mathrm{s}^{2}$ (p. 16)

Há, na raiz do protesto de McCloskey contra o "abuso" de contrafactuais em Economia, uma confusão entre questões lógicas e metafísicas. Procurando explicar porque um modelo pode entrar em contradição com a história, ele escreve:

"Um mundo em que a Inglaterra de 1780 não produziu uma revolução industrial seria um mundo bem diferente, tanto antes quanto depois de 1780. (vide supra)"

É esta a razão oferecida por McCloskey para que seja logicamente contraditório imaginar a história inglesa sem uma revolução industrial. A razão é metafísica. (E uma metafísica, no mínimo, duvidosa.) Segundo MoCloskey não teria havido uma revolução industrial apenas se a história inglesa, antes e depois de 1780, fosse diferente da real história inglesa, antes e depois de 1780. Fm outras palavras, a revolução industrial e suas sequelas estavam determinadas pela história inglesa de antes de 1780 . "Portanto", adverte MbCloskey, não se deve especular sobre a história inglesa sem uma revolução industrial. Assim sendo, o sentido em que McCloskey perverte a expressão "contradição lógica" fica claro: falar da Inglaterra sem 
uma revolução industrial é falar de uma "impossibilidade" metafísica. Aquela sentença ("Um mundo em que...") é estranha por pelo menos uma outra razão. Embora supostamente explique o que há de errado com os contrafactuais, ela pode ser lida como um contrafactual: se não tivesse havido uma revolução industrial, a história da Inglaterra teria sido diferente ${ }^{(9)}$.

Segunda objeção: McCloskey defende doutrinas incompatíveis.

Como acabamos de notar, McCloskey em Storytelling in economics, se revela um determinista. Aqui, vamos argumentar que, com relação a questões metafísicas, ele não pode ser consistente. Em The Rhetoric of Economics, MoCloskey critica o falsificacionismo popperiano (que ele considera "modernista") na base do fato de que, dado um explanandum falso, não é possível localizar, entre as hipóteses principais e auxiliares nos quais ele repousa, a hipótese que foi falseada. E prossegue :

Mesmo se a hipótese (a falseada) em questão pode ser isolada, a natureza probabilística das hipóteses, especialmente em economia, torna experimentos cruciais não-cruciais: o acaso é a alternativa sempre presente... Isto, os próprios falsificacionistas há muito reconheceram, e há muito lamentam. A falsificação, para todos os efeitos, foi falseada. ${ }^{(10)}$

A objeção de MoCloskey não é muito clara. Sugerimos duas interpretações: ou MoCloskey rejeita o falsificacionismo porque há eventos nãodeteminados, ou, embora mantenha a posição que defendia em Storytelling, ele vê explicações probabilísticas - e, portanto, não-falseáveis - como científicas. Mas ambas essas alternativas carregam dificuldades para MoCloskey. Se ele abraça o indeterminismo, é razoável recusar a falseabilidade como condição necessária de uma explicação científica. Mas se é esta a crítica de MoCloskey, ele se expõe a censuras - dada sua posição em Storytelling - de sustentar doutrinas metafísicas incompatíveis, segundo suas conveniências retóricas: ele adbta o deteminismo para criticar o uso de contrafactuais em economia, e invoca o indeterminismo contra Popper e o metro modernista. Que se considere, agora, a segunda ( $\mathrm{e}$, quer me parecer, forçada) interpretação: vamos supor que McCloskey é um determinista que rejeita a falseabilidade como condição necessária da explicação científica. Qual poderia ser o seu problema? Se vale o determinismo, uma explicação probabilística é uma explicação incompleta: o deteminista sustenta que para cada evento há um conjunto de circunstâncias que o tornam necessário; uma explicação probabilística, no entanto, não proíbe nenhum evento e, portanto, não identifica circunstâncias determinantes. Agora, conhecer as circunstâncias determinantes equivale a possuir uma explicação falseável - uma explicação que proíbe alguns eventos. O falsificacionismo metodológico seria, ao que parece, um complemento natural para o determinismo metafísico: para o deteminista, apenas explicações falseáveis podem ser inteiramente satisfatórias ${ }^{(11)}$.

Terceira objeção: os textos de MoCloskey tergiversam, e seus argumentos freqüientemente perdem de vista seus alvos.

Para exemplificar o caráter digressivo do estilo de McCloskey, vamos acompanhá-lo em algumas páginas de The Rhetoric of Economics ${ }^{(12)}$, onde ele se dispõe a esmiuçar o domínio do modernismo em economia.

MoCloskey cita, como evidência dessa influência, a notoriedade dos textos metodológicos da Escola de Chicago, particularmente da Methodology of positive economics, de Milton Friedman. Tal influência surpreende MoCloskey: com relação a questões não-metodológicas, a Escola de Chicago irrita os economistas. Mais ainda, segundo MoCloskey, Friedman não é um modernista integral: ele propõe critérios estéticos de escolha de teorias ("simplicidade e fertilidade"), e ele peca contra os preceitos modemistas ao confessar o interesse de questionários e a ascendência da comunidade científica sobre as crenças de seus membros. MoCloskey prossegue:

"... Friedman, como Karl Popper, outra figura de transição, parecia lutar para escapar da camisa-de-força do positivismo e de suas tradições intelectuais, embora apenas com sucesso esporádico." (13) 
A seguir, McCloskey menciona um artigo "persuasivo", segundo o qual a Methodology of positive economics de Friedman defende um ideário antes vinculado ao pragmatismo que ao positivismo. Friedman, nos é dito, concorda com essa interpretação. Talvez Friedman não seja, afinal, um modernista.

MoCloskey procura recuperar o terreno perdido: as reais posições de Friedman não precisam ser levadas em conta, o que importa, para Mocloskey, é o fato de que Friedman é geralmente tido como positivista:

...comentários espontâneos no calor da argumentação econômica normalmente têm um conteúdo cruamente modernista, freqüientemente se valendo das palavras de Friedman. (14)

Por exemplo, um artigo importante de Richard Roll e Stephen Ross sobre finanças... afi ma que a 'teoria deve ser testada por suas conclusões, não por seus pressupostos', e que 'do mesmo modo, não se devem rejeitar as conclusões derivadas da maximização do lucro empresarial na base de levantamentos nos quais a gerência pretende que trocam o lucro pelo benefício social. ${ }^{(15)}$

E McCloskey cita William Sharpe, para quem

"... o realismo dos pressupostos pouco importa. Se as implicações são razoavelmente consistentes com os fenômenos observados, podese dizer que a teoria ‘explica' a realidade."(16)

Ambos os artigos defendem que a teoria deve ser julgada por seus frutos, não por seu realismo. Mas, como vimos, Mocloskey vê esta máxima como estética antes do que como modernista. Prima Facie, antes que estético ou positivista, o critério é pragmático. Mais ainda, ele não corresponde a nenhuma das exortações modemistas listadas por McCloskey (The Rhetoric of Economics, pp. 7/8) (17) . O repúdio aos questionários é, segundo MoCloskey, uma regra modernista; no entanto, eles são vistos como interessantes, com restrições, por Friedman (assim sendo, este repúdio não é um bom exemplo de leitura positivista das "palavras de Friedman" por seus epígonos) e, mais ainda, a nomma não é essencialmente positivista. Ela reflete, antes, o incômodo dos economistas frente à incompatibilidade entre, por exemplo, suas descrições do comportamento dos empresários e o relato dado por estes.

Mas, para McCloskey, a evidência decisiva da ascendência do modernismo em Economia é o fato de que os economistas "vibrariam com o epíteto de Cientista modernista". Brincadeiras à parte, há pelo menos uma boa razão para não aceitar tal evidência: mesmo se o epíteto agrada, não se segue que os economistas aceitem as regras que McCloskey considera modernistas: embora tenha descrito sua metodologia como positiva, Friedman agora prefere o adjetivo "pragmática".

O argumento de McCloskey não é apenas digressivo: ele não é persuasivo (pobre retórica!) , e, pior, é suicida. Lembremos que uma das dbjeçães de MoCloskey ao falsificacionismo era que as hipóteses auxiliares protegem a teoria da falseação. Mas, em MoCloskey, as hipótese auxiliares têm o papel contrário: suas hipótese auxi liares (sobre o caráter irritante da Escola de Chicago e sobre a real postura metodológica de Friedman), ao invés de proteger sua polêmica (que o modernismo impera em Economia) da falseação, tende a falseá-la: suas hipótese auxiliares formam, como diria Lakatos, "um escudo destrutivo".

Abstract: MoCloskey's call for a philosophical reappraisal of the rhetoric of economics is discussed. B. Prado (I and II) argues that a theory of rhetoric for which "anything goes" should not be infered from MbCloskey's critique of positivism. In III (M. Julian Cass) some philosophical aporiae in MoCloskey texts are examined.

Keywords: economics - philosophy of economics - positivism - rhetoric. 


\section{Notas}

(1) 1985, p. ix.

(2) Do mesmo modo, tentamos mostrar a incompatibilidade entre a análise experimental do comportamento e a epistemologia carnapiana com a qual ela é normalmente associada. Aqui também, a insistência numa linguagem observacional se revela ser um cul-de-sac teórico. Percebemos que as escaramuças teóricas eram multiplicadas pelos epígonos, metodologicamente mais disciplinados que seus mestres. Poder-se-ia dizer de Skinner o que MoCloskey diz de Milton Friedman isto é, que ele é menos "xiita" do que seus discípulos. Desde seu Case History, Skinner insistia em uma quase-teoria da ciência que fazia a "pesquisa dirigida por contingências" prevalecer sobre a "pesquisa dirigida por regras", de uma forma que se pode considerar próxima a Feyerabend, antes que este publicasse seu discurso contra o método.

(3) Q. cit., 1985, p.16.

(4) Lebrun, Gérard - La Boutade de Charring Cross, Manuscrito, NOI, NO2, AbriI 1978.

(5) Qp. cit., 1985, p. 16.

(6) Storytelling in Economics, versão de agosto de 1987, pp. 4-5.

(7) . Claudius, Claudius, the God. Penguin Books, 1986, p. 325.

(8) Ibid. p. 325 (o grifo é nosso)

(9) Nossa crítica dos equívocos de Mocloskey acerca de contrafactuais se baseia na definição clássica da implicação por tabelas-de-verdade. Tal definição, que deu margem a muita controvérsia, foi por nós adotada tendo em vista que MoCloskey qualifica sua objeção como "lógica". Assim sendo, nossa crítica consiste simplesmente em que ele se equivoca na determinação do problema. Se fosse nosso propósito considerar os contrafactuais independentemente da visão de Mocloskey, uma discussão da definição por tabelas-de-verdade se faria necessária. Aqui, basta mencionar que enfoques razoáveis de sentenças condicionais não precisam conformar-se a esta (ou a qualquer) definição por tabelas-de-verdade.
Seja lá como for, tanto quanto saibamos, há pelo menos uma espécie de sentença condicional que seria inquestionavelmente descrita como uma 'contradição lógica' : aquela cujo antecedente é uma tautologia e o conseqüente uma contradição. Mas tais proposiçães, por definição, não são contrafactuais.

(10) Op. cit., 1985, p. 15.

(11) As aporias de McCloskey não devem ser atribuídas a Popper. Desde Logic of Scientific Discovery, Popper via teorias probabilísticas como científicas, desde que satisfeitas certas condições. Nesta primeira e capital obra sobre falsificacionismo, a não-falseabilidade de teorias probabilísticas era reconhecida, mas não lamentada. Razão: Popper distinguia questões epistemológicas de questões metafísicas.

(12) Op. cit., 1985, po. 8-11.

(13) Ibid., p. 10.

(14) Ibid., p. 10

(15) Ibid., p. 10.

(16) Ibid., p. 11.

(17) O critério difere da segunda regra modernista, "Apenas as implicações (ou predições) observáveis de uma teoria importam para suas verdade" (p. 7), a menos que "verdade" seja entendida na sua acepção pragmática. Mas, como vimos, MoCloskey vê o positivismo e o pragmatismo como doutrinas conflitantes. 